\title{
Fucosidosis: genetic and biochemical analysis of eight cases
}

Helen Cragg, Magali Williamson, Elisabeth Young, John O'Brien, Jack Alhadeff, Suzanne Fang-Kircher, Eduard Paschke, Bryan Winchester

\section{Division of}

Biochemistry and

Genetics, Institute of Child Health, (University of London), 30 Guilford Street, London WC1N 1EH, UK

H Cragg

$M$ Williamson

E Young

B Winchester

Department of Neurosciences, University of

California, San Diego, La Jolla, California 92093, USA

J O'Brien

Department of Chemistry, Lehigh University, Bethlehem, PA 18015, USA

J Alhadeff

Institute of Medical Chemistry, University of Vienna, Wahringer

Strasse 10, A-1090

Vienna, Austria

$S$ Fang-Kircher

Institute of

Biochemistry,

University of Graz,

Auenbruggerplatz 30,

A-8036 Graz, Austria

E Paschke

Correspondence to:

Dr Winchester.

Received 10 April 1996 Revised version accepted for publication

13 September 1996

\begin{abstract}
The molecular basis of the deficiency of $\alpha$-L-fucosidase has been investigated in eight patients who had been diagnosed clinically and enzymatically as suffering from the autosomal recessive lysosomal storage disease fucosidosis. None of the patients had a deletion or gross alteration of the $\alpha$-L-fucosidase gene (FUCA1). Single strand conformation polymorphism (SSCP) analysis followed by direct sequencing of amplified exons and flanking regions identified putative disease causing mutations in six of the patients, who had severe forms of the disease and very low residual $\alpha$-L-fucosidase activity and protein. They were a 10 bp deletion in exon 1 (E113fs), a 1 bp deletion at position -2 of intron 2 (S216fs), a $\mathrm{g} \rightarrow \mathbf{a}$ transition at IVS5+1, point mutations W183X and $\mathrm{N} 329 \mathrm{Y}$ in exons 3 and 6, respectively, and a compound allele consisting of a point mutation in the signal peptide in exon 1 , P5R, and a 1 bp insertion in exon 6 (Y330fs). One patient in whom an SSCP change was not detected had residual $\alpha-L$ fucosidase activity and cross reacting protein in the heterozygous range and normal metabolism of metabolites containing fucose in his fibroblasts, consistent with the low activity polymorphism. The eighth patient, who had a partial deficiency of $\alpha$-L-fucosidase in her fibroblasts and leucocytes at a young age but normal $\alpha$-Lfucosidase activity and protein at a later age, was homozygous for the common Q281R polymorphism in exon 5 . She had no other sequence changes and Kivlin (Peters plus) syndrome has subsequently been diagnosed. The basis of her transient deficiency of $\alpha$-L-fucosidase is not known. The detection of five novel mutations in six severely affected patients confirms the genetic heterogeneity in fucosidosis. $(7$ Med Genet 1997;34:105-110)
\end{abstract}

Keywords: fucosidosis; $\alpha$-fucosidase; mutations.

Fucosidosis is the lysosomal storage disease resulting from a deficiency of the enzyme $\alpha-\dot{\mathrm{L}}$ fucosidase (EC.3.2.1.51). ${ }^{12}$ The deficiency of this enzyme results in the accumulation in tissues and excretion in the urine of partially catabolised oligosaccharides, glycoasparagines, and glycolipids with $\alpha$ linked fucose at the nonreducing end of the glycan chains. This accumulation leads to the clinical features, which include mental and growth retardation, neurological deterioration, coarse facies, recurrent infections, skeletal abnormalities and joint contractures, visceromegaly, hearing loss, and angiokeratoma. ${ }^{3}$ Patients vary considerably, even within families ${ }^{4}$ in the age of onset and severity of symptoms, indicating underlying genetic heterogeneity. There is no cure for fucosidosis, although a bone marrow transplantation (BMT) was carried out recently ${ }^{5}$ after encouraging results for BMT in the canine model of fucosidosis. ${ }^{6}$

The $\alpha$-fucosidase gene (FUCA1) has been localised to chromosome 1p.36.1-p.34.1 ${ }^{7}$ and contains eight exons dispersed over $22 \mathrm{~kb}^{8}$ The cDNA for $\alpha$-fucosidase has 2053 bp with an open reading frame for 461 amino acids including a putative signal peptide of 22 amino acids. ${ }^{9}{ }^{10}$ A pseudogene (FUCAIL) on chromosome 2 is colinear with at least $70 \%$ of the $\alpha$-fucosidase cDNA but it lacks intronic sequences. ${ }^{7}$ This permits amplification of the functional gene exons for mutation analysis using primers based on intronic sequences. A locus on chromosome 6 (FUCA2) linked to the plasminogen locus regulates the level of $\alpha$-fucosidase in plasma ${ }^{11-13}$ and fibroblast ${ }^{14}$ but not in leucocytes. There is no homology between FUCA1 and FUCA2. Definitive enzymatic diagnosis of fucosidosis is therefore based on measurement of $\alpha$-fucosidase in leucocytes. Several putative disease causing mutations have been reported in fucosidosis. ${ }^{3}{ }^{15-23}$ Here, we present the biochemical characterisation and mutation analysis for eight patients who had been diagnosed enzymatically and clinically as having fucosidosis.

\section{Methods}

PATIENTS

All the patients had been diagnosed as having fucosidosis by the finding of decreased $\alpha$-Lfucosidase activity in white blood cells, fibroblasts, or serum to confirm a preliminary clinical diagnosis. Details of the patients are given in table 1 and in the Discussion.

\section{ASSAY OF $\alpha$-FUCOSIDASE ACTIVITY IN} FIBROBLASTS AND LEUCOCYTES

Leucocytes were isolated from heparinised blood and cultures of skin fibroblasts established as described previously. ${ }^{24}$ Lymphoblastoid cell lines were established by viral transformation at the National Microbiological Research Centre, Porton Down, Wiltshire, UK. The $\alpha$-fucosidase activity was measured in 
Table 1 Summary of patients analysed

\begin{tabular}{|c|c|c|c|c|c|c|c|c|}
\hline Patient No & Ethnic origin & $\begin{array}{l}\text { Mutation } \\
\text { (exon) }\end{array}$ & Base change & Amino acid change & Restriction site & $\begin{array}{l}\text { a-fucosidase activity } \\
\text { in fibroblasts } \\
\text { (nmol/h/mg)t }\end{array}$ & $\begin{array}{l}\text { CRIM \% } \\
\text { (fibroblasts)* }\end{array}$ & $\begin{array}{l}\text { Clinical } \\
\text { phenotype }\end{array}$ \\
\hline 1 & German & None & - & - & - & 72.0 & 36.2 & Mild \\
\hline 2 & Asian & IVS5+1 (5) & $\mathrm{g} \rightarrow \mathrm{a}$ & - & TaqI & 0.2 & - & Severe \\
\hline 3 & Austrian & E113fs (1) & $\begin{array}{l}\text { Deletion of nt } \\
340-349 \ddagger\end{array}$ & 10 aa altered before stop & - & 6.0 & - & Severe \\
\hline 4 & British & S216fs (3) & $\mathrm{AGC} \rightarrow \mathrm{GC}$ & 5 aa altered before stop & - & 0.6 & 7.5 & Not known \\
\hline 5 & Austrian & W183X (3) & $\mathrm{TGG} \rightarrow \mathrm{TGA}$ & Trp $\rightarrow$ stop & HinfI & 1.0 & - & Severe \\
\hline 6 & Asian & $\begin{array}{l}\text { P5R (1) } \\
\text { Y330fs (6) }\end{array}$ & $\begin{array}{l}\mathrm{CC} \overline{\mathrm{G}} \rightarrow \mathrm{CG} \overline{\mathrm{G}} \\
\mathrm{TAT} \rightarrow \mathrm{T} \overline{\mathrm{TAT}}\end{array}$ & $\begin{array}{l}\text { Pro } \rightarrow \text { Arg } \\
9 \text { aa altered before stop }\end{array}$ & HaeIII & 1.0 & 6.9 & $\begin{array}{l}\text { Moderate to } \\
\text { severe }\end{array}$ \\
\hline 7 & British & None & - & - & - & 27.0 & 117 & Mild \\
\hline 8 & Austrian & N329Y (6) & $\underline{\mathrm{AAC}} \rightarrow \underline{\mathrm{TAC}}$ & Asn $\rightarrow$ Tyr & - & 2.0 & - & Severe \\
\hline
\end{tabular}

* Percentage of cross reacting material relative to amount in control cells $(\mathrm{n}=3)$ at a total protein concentration of $40 \mu \mathrm{g} / \mathrm{ml}$

† Normal reference range $27-229 \mathrm{nmol} / \mathrm{h} / \mathrm{mg}$.

$\ddagger$ Nucleotide numbers based on 1 for the $\mathrm{A}$ in initiation codon.

all cells using the synthetic fluorigenic substrate, 4-methylumbelliferyl $\alpha$-L-fucoside. ${ }^{19}$

QUANTITATIVE MEASUREMENT OF $\alpha$-FUCOSIDASE PROTEIN BY A DOUBLE ANTIBODY SANDWICH ELISA TECHNIQUE

Fifty microlitres of a solution of polyclonal goat anti-human $\alpha$-L-fucosidase $\operatorname{IgG}^{25}(20 \mu \mathrm{g} / \mathrm{ml}$ in PBS) was put in the well of a microtitre plate with $50 \mu \mathrm{l}$ PBS in control wells. The plates were incubated at room temperature for 1.5 hours. The wells were washed twice with PBS and then $250 \mu$ l of blocking solution (BSA $3 \%(w / v)$ in sodium azide $0.02 \%(\mathrm{w} / \mathrm{v})$ ) was added to each well. The plates were incubated at room temperature overnight and then washed twice with PBS. Then $50 \mu \mathrm{l}$ of extracts of sonicated fibroblasts or lymphoblasts which had been diluted to $20 \mu \mathrm{g} / \mathrm{ml}, 40 \mu \mathrm{g} / \mathrm{ml}$, or $80 \mu \mathrm{g} / \mathrm{ml}$ in blocking solution were added with PBS in the control wells. The plates were incubated for 1.5 hours at room temperature then washed four times with PBS.

Fifty microlitres of monoclonal rat antihuman $\alpha$-L-fucosidase IgG, ${ }^{26}$ diluted 1000 fold in blocking solution, was then added, again using PBS as control. After incubation for 1.5 hours at room temperature the wells were washed four times with PBS. Then $100 \mu \mathrm{l}$ of alkaline phosphatase conjugated goat anti-(rat IgG serum), diluted 500 times in blocking solution, was added to each well. The plates were incubated for one hour and then washed four times with PBS, followed by twice with 10 $\mathrm{mmol} / 1$ diethanolamine, $\mathrm{pH} 9.5$, containing 0.5

Table 2 Primers used for PCR

\begin{tabular}{lll}
\hline Primer number & Primer sequence & Primer position \\
\hline $1^{\star}$ & 5' GCC GCC CGC GGG CAC CTG CGC GTT AA 3' & 5' untranslated \\
2 & 5' GCC GCC CAG CCC CAC CTC CTG 3' & Intron 1 \\
$3^{\star}$ & 5' TCA GGC ATG CTG GGC AAG TTC A 3' & Intron 1 \\
4 & 5' GAG GAG GTA CAG AAC TCT TGA CAG 3' & Intron 2 \\
$5^{\star}$ & 5' AAT GCT AGA ACT GAT TTT CCT TAA 3' & Intron 2 \\
6 & 5' TTA ATG GTA CCC TAT AGG AAG 3' & Intron 3 \\
$7^{\star}$ & 5' AAT GGT CCA TAA GAT TTT ACT GCT AAC 3' & Intron 3 \\
8 & 5' ACT CCA GAG TTT GGC TCC TTG 3' & Intron 4 \\
$9^{\star}$ & 5' GAT GAG GTG GTA GTA AAT GA 3' & Exon 5 \\
10 & 5' AAA TGA TTT CAG ATT CTT C 3' & Exon 5 \\
$11^{\star}$ & 5' GCT GTC CTG TGC ATT GTA 3' & Intron 4 \\
12 & 5' AGC TTT TGA ACA TTA TAT 3' & Intron 5 \\
$13^{\star}$ & 5' TAA GCA TGA TGC CAG GCT TG 3' & Intron 5 \\
14 & 5' AGG AGA TAC CAG TTC CGG AT 3' & Intron 6 \\
$15^{\star}$ & 5' GGA GGA AAT GTA TAA AGT TGT ATA TCA 3' & Intron 6 \\
16 & 5' AGG GAA GGA AGA AAG GAA GGA T 3' & Intron 7 \\
$17^{\star}$ & 5' TCC TAC CAT AGT CAG CCT GT 3' & Intron 7 \\
18 & 5' AAA CAG TGA GCA GCG CCT CT 3' & 3 non-coding \\
\hline${ }^{*}$ Biotinylated. & &
\end{tabular}

$\mathrm{mmol} / \mathrm{l} \quad \mathrm{MgCl}_{2}$. Then $50 \mu \mathrm{l}$ of substrate solution, $1 \mathrm{mg} / \mathrm{ml}$-nitrophenyl phosphate in $10 \mathrm{mmol} / 1$ diethanolamine, was added to each well and the plates were incubated for two hours or overnight at room temperature. The absorbance at $405 \mathrm{~nm}$ of the released $p$-nitrophenol was measured using an ELISA plate reader.

\section{SOUTHERN BLOT ANALYSIS}

Radiolabelled $\alpha$-fucosidase cDNA probes and genomic DNA were prepared and used for Southern blot analysis as described previously. ${ }^{19}$

POLYMERASE CHAIN REACTION (PCR)

Exons 1 to 8 of the $\alpha$-fucosidase gene were amplified by PCR using the primers and conditions listed in tables 2 and $3 .{ }^{19}$ Radiolabelled amplification products were obtained by the incorporation of $\alpha-{ }^{32} \mathrm{P}-\mathrm{dCTP}$ during the amplification reaction. The amplified product of exon 1 ( $513 \mathrm{bp}$ ) was digested to fragments of 194 and $319 \mathrm{bp}$ with the restriction enzyme NotI before SSCP analysis.

SINGLE STRANDED CONFORMATIONAL

POLYMORPHISM (SSCP) ANALYSIS

Radiolabelled PCR products were denatured at $94^{\circ} \mathrm{C}$ for five minutes and then analysed by electrophoresis in a $6 \%$ non-denaturing polyacrylamide gel for 14 to 18 hours at $4^{\circ} \mathrm{C}$ or room temperature and the bands detected by autoradiography. ${ }^{19} 27$

SEQUENCING OF PCR AMPLIFIED PRODUCTS

The amplified products of each exon were sequenced by a number of methods. Exons 2, 5,7 , and 8 were sequenced using the Dynal

Table 3 Conditions for PCR

\begin{tabular}{|c|c|c|c|c|c|}
\hline $\begin{array}{l}\text { Exon } \\
\text { number }\end{array}$ & $\begin{array}{l}\text { Primer } \\
\text { pair }\end{array}$ & $\begin{array}{l}P C R \\
\text { product } \\
\text { (bp) }\end{array}$ & $\begin{array}{l}\text { Annealing } \\
\text { temp }\left({ }^{\circ} \mathrm{C}\right)\end{array}$ & DMSO & $\begin{array}{l}\mathrm{Mg}++ \\
(\mathrm{mmol} / \mathrm{l})\end{array}$ \\
\hline 1 & 1,2 & $194,319^{\star}$ & 61 & $10 \%$ & 1.0 \\
\hline 2 & 3,4 & 275 & 57 & - & 1.5 \\
\hline 3 & 5,6 & 290 & 50 & - & 1.5 \\
\hline 4 & 7,8 & 198 & 57 & - & 1.5 \\
\hline 5 & $9,10 \dagger$ & 201 & 49 & - & 1.5 \\
\hline 5 & 11,12 & 538 & 49 & - & 1.5 \\
\hline 6 & 13,14 & 315 & 57 & - & 1.5 \\
\hline 7 & 15,16 & 249 & 61 & - & 1.5 \\
\hline 8 & 17,18 & 257 & 60 & - & 1.5 \\
\hline
\end{tabular}

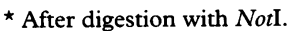

t Exonic primers. 
Table 4 Haplotypes for PvulI and BglI polymorphisms

\begin{tabular}{llll}
\hline \multirow{3}{*}{ Patient } & \multicolumn{2}{l}{ Fragment } & \\
\cline { 2 - 3 } & PvuII & BglI & Haplotype \\
\hline 1 & N/A & N/A & N/A \\
2 & $1-1$ & $1-1$ & $(1-1)(1-1)$ \\
3 & $2-2$ & $2-2$ & $(2-2)(2-2)$ \\
4 & $1-1$ & $1-1$ & $(1-1)(1-1)$ \\
5 & N/A & $1-2$ & N/A \\
6 & $1-1$ & $2-2$ & $(1-2)(1-2)$ \\
7 & $2-2$ & $2-2$ & $(2-2)(2-2)$ \\
8 & N/A & $1-1$ & N/A \\
\hline
\end{tabular}

Band sizes seen on Southern blot. PvuII $1=7.0 \mathrm{~kb} ; 2=6.0 \mathrm{~kb}$ $B g I \mathrm{I} 1=12.0 \mathrm{~kb} ; 2=6.5 \mathrm{~kb}+5.5 \mathrm{~kb}$.

streptavidin bead technology as previously described. ${ }^{19}$ Exon 3 was analysed using the Stratagene Cyclist Exo-pfu DNA sequencing kit according to the manufacturer's instructions; $200 \mathrm{fmol}$ of PCR product was sequenced using $1 \mathrm{pmol}$ of primer incorporating $10 \mu \mathrm{Ci}$ of $\alpha^{35}$ S-dATP and 2.5 units of Exo-pfu polymerase. The temperature programme used for sequencing was the same as that used for the initial PCR amplification. Exons 1 and 6 were cloned into the pGEM-T vector (Promega) according to the manufacturer's instructions. The nucleotide sequence of the inserts was determined by the dideoxy nucleotide chain termination method. Nucleotide sequences were obtained from three independent PCR amplification reactions.

\section{Results}

SOUTHERN BLOT ANALYSIS

Genomic DNA from the patients was analysed by Southern blotting to detect any gross gene rearrangements and to determine the haplotype of the patients for two common restriction fragment length polymorphisms observed after digestion with PvuII and $B g I I$ (table 4). No gross gene deletions or rearrangements were observed using a panel of restriction enzymes indicating that the mutations were either microdeletions, microinsertions, or point mutations. This excluded the occurrence of the previously described large deletion of the 3 ' end of the genes. ${ }^{3}$ A specific change in the band pattern was observed for DNA from patient 2 on digestion with TaqI. This has been shown previously by us to result from a mutation in the 5 ' splice site of intron $5 .^{19}$

The recurrent mutation Q422X, which has been found in 10 patients with the haplotype $(2-2)(2-2)$ (table 4) from six unrelated families $^{15}$ was not detected by Southern blotting in our patients 3 and 7 with the same haplotype. This was confirmed by the specific amplification of exons 7 and 8 using primers 15 and 18 in intron 6 and in the $3^{\prime}$ non-coding region, respectively (table 1 ), and subsequent digestion with $E c o$ RI.

DETECTION OF SEQUENCE CHANGES BY SSCP The eight exons of FUCA1 and their flanking regions were amplified from genomic DNA from patients and controls by PCR using pairs of intronic primers (tables 2 and 3). Amplified material of the expected sizes was obtained for each exon from all the patients, confirming that no gross deletions of the gene were present.
These observations, together with the results of Southern blot analysis, suggest that the mutations in the patients are single base changes or small insertions or deletions.

The radiolabelled PCR products were analysed directly by SSCP, except for the PCR product of exon 1, and altered band patterns were observed in seven out of eight of the patients, patient 1 being the exception. Patients 3 and 7 appeared to be homozygous and patient 5 heterozygous for the characteristic band pattern associated with the polymorphism Q281R. ${ }^{28}$ This was the only abnormal pattern seen for patient 7 . Surprisingly only one patient, patient 6 , showed conformational changes in more than one exon (excluding the Q281R polymorphism). This suggested that either the patients were homozygous for a single sequence change or that two different allelic changes occurred in the same exon but the SSCP band patterns were not complex enough for the latter explanation. It is also possible that other sequence changes did not produce a conformational change detectable under the conditions used. Thus non-polymorphic sequence changes were detected in all the patients except patients 1 and 7 .

\section{DETECTION OF MUTATIONS BY SEQUENCING}

The PCR products showing SSCP changes were sequenced and sequence changes were detected in all the products analysed (table 1). All the sequence changes were present in a homozygous form including those in patient 6 , who had sequence changes in both exons 1 and 6 . No other sequence changes were detected in the amplified exons that were sequenced apart from the CG transversion in exon 5 responsible for the Q281R polymorphism. In some cases, exons in which an SSCP change had not been detected were sequenced but no further sequence changes were found.

Several of the sequence changes abolished or created sites for restriction enzymes in the amplified sequences, permitting confirmation of the presence of the mutations by restriction analysis (table 1). The P5R mutation was shown to be homozygous in patient 6 and heterozygous in both his parents by digestion with HaeIII. A unique HinfI site is created by the W183X mutation in patient 5 and this was exploited to confirm the homozygosity of this mutation in the patient. The splice site mutation in the 5 ' splice of intron 5 in patient 2 can be detected because it creates a new TaqI site. This mutation was first detected by Southern blotting using this enzyme and can be readily detected by amplifying exon 5 and its flanking regions followed by digestion with TaqI. ${ }^{19}$ The presence of the Q281R polymorphism was also confirmed in patients 3,5 , and 7 by digestion of exon 5 with $B s a J^{28}{ }^{28}$

EFFECT OF MUTATIONS ON $\alpha$-FUCOSIDASE The $\alpha$-fucosidase activity in fibroblasts from the patients was measured using the synthetic fluorigenic substrate, 4-methylumbelliferyl $\alpha$-L-fucopyranoside (table 1 ). The two patients, 1 and 7, in whom an SSCP change had not been detected had activities well within or 
at the bottom of the normal reference range, respectively. In contrast, the six patients in whom a putative mutation had been found had $\alpha$-fucosidase activity well below the normal reference range. These results suggest that the detected sequence changes had decreased the $\alpha$-fucosidase activity.

The amount of protein cross reacting with antibodies raised against purified human liver $\alpha$-fucosidase was measured in two of the fucosidosis patients with negligible residual activity, 4 and 6 , and in the two patients, 1 and 7 , with high residual activity, using a double antibody ELISA method (table 1). Patients 4 and 6 had very low concentrations of cross reacting material, 7.5 and $6.9 \%$ of the mean measured in controls, respectively. Willems et $a l^{\beta}$ found the residual $\alpha$-fucosidase protein to be below $6 \%$ of the normal mean in lymphoblastoid cells of 23 fucosidosis patients. Patient 1 had an intermediate level of CRIM (36\% of control fibroblasts) and patient 7 a normal level.

\section{Discussion}

Two patients were homozygous for missense mutations. The N329Y mutation in patient 8 substitutes a tyrosine for an asparagine residue that is conserved in $\alpha$-fucosidases from human, rat and Diclyostelium discoideum, ${ }^{29}$ and $\operatorname{dog}^{30}$ The change from a small neutral to a larger hydrophobic side chain would be expected to disrupt the conformation of this highly conserved region and to affect the $\alpha$-fucosidase activity. Asparagine 329 is not part of an $\mathrm{N}$-glycosylation sequon. Patient 8 had a severe form of the disease dying at 3 years 4 months but with initial mild symptoms followed by a rapid and fatal deterioration. ${ }^{31}$

Patient 6 was homozygous for a missense mutation, $\mathrm{P} 5 \mathrm{R}$, in exon 1 and a single base insertion in exon 6 (Y330Fs). Both his parents are heterozygous for the two mutations, indicating that they are on the same chromosome. Substitution of the neutral and nonpolar amino acid, proline, by the basic and polar amino acid, arginine, would be expected to alter the folding or chemical topography of the polypeptide chain. This substitution is at the first residue of the hydrophobic core of the 22 amino acid signal peptide of $\alpha$-fucosidase and might be expected to impair the translocation of the nascent preproenzyme through the endoplasmic reticulum membrane. The effect of a mutation in the signal peptide sequence on the intracellular transport of a lysosomal enzyme is not well understood because such mutations are not common. A missense mutation, A20P, in the signal peptide of $\alpha$-galactosidase has been shown to lead to a moderate decrease in mRNA in an atypical variant of Fabry disease ${ }^{32}$ and a 1 bp deletion at codon 15 in the signal peptide sequence of iduronate 2-sulphatase has been reported to lead to a mild form of Hunter disease. ${ }^{33}$ At least three non-pathogenic polymorphisms have been found in the signal peptide sequence of $\alpha$-L-iduronidase ${ }^{34}$ and it has been suggested that such polymorphisms may contribute to the normal variation in enzymatic activity or exac- erbate the effect of another sequence change in the gene. The other sequence change in the compound mutant allele of patient 6 is the insertion in exon 6 of a thymine leading to a frameshift and the formation of a premature stop codon, TAA, nine amino acids downstream within the exon. This change could lead to loss of enzymatic activity either by the formation of a truncated protein or by exon skipping. Although patient 6 had severe symptoms he survived to 15 years, suggesting that the low residual activity and cross reacting material $(6.9 \%)$ produced by this compound allele was partially effective.

The $g \rightarrow$ a transition at the +1 position of the $5^{\prime}$ donor splice site of exon 5 in patient 2 was shown to be homozygous by family studies. ${ }^{19}$ Both parents, who are distantly related, were carriers of the mutation, which cosegregated with the fucosidosis allele in other family members, indicating strongly that this is the disease causing mutation in this family. Calculation of the likelihood of the use of the normal and mutant splice sites, according to Shapiro and Senepathy, ${ }^{35}$ indicated that the mutation would lower the likelihood score from 86 to 68 . Analysis of the sequence of exon 5 did not show any cryptic splice sites with a higher probability of usage than the mutated splice site. Therefore, exon 5 would probably be spliced out leading to a frameshift in the truncated protein or use of a cryptic intronic site, both of which would explain the deficiency of $\alpha$-fucosidase. The patient is now aged 13.5 years but is deteriorating rapidly.

The second identified splice site mutation was deletion of adenine at position -2 of intron 2 (S216fs) in patient 4. This mutation, which was homozygous in the patient, was predicted to have two possible effects. Firstly, it may affect splicing, but the likelihood score for the use of the splice site only decreased from 94 to 87 , suggesting that the alteration to the reading frame would be more important. The frameshift changes the amino acid sequence from SYKPDL to AINLITERM, that is, the creation of a premature stop codon 5 amino acids downstream from the affected codon. Homozygosity for this mutation resulted in very little resdual enzymatic activity and protein $(7.5 \%)$ and a severe form of the disease. This mutation has been found in a heterozygous state in a Belgian patient, ${ }^{18}$ in whom the other mutation is unknown.

Patient 5 is homozygous for the nonsense mutation, W183X, which could result in a truncated protein or, more likely, a severe decrease in the level of mRNA. There is negligible $\alpha$-fucosidase in fibroblasts from this patient, who was severely physically and mentally retarded at the age of 7 years but who did not deteriorate significantly over the next two years. ${ }^{36}$

The 10 bp deletion in exon 1 (E113fs), which is homozygous in patient 3 , also results in a premature termination codon, in frame, 10 amino acids downstream from the beginning of the deletion in codon 114. A three base pair repeat of GAG or GGA involving the first two of the deleted base pairs could be the cause of 
Table 5 a-fucosidase activity in leucocytes ands plasma of patient 7 at different ages

\begin{tabular}{|c|c|c|}
\hline Age & $\begin{array}{l}\text { Leucocytes } \\
\text { (nmol/h/mg) }\end{array}$ & $\begin{array}{l}\text { Plasma } \\
(\mathrm{nmol} / \mathrm{h} / \mathrm{ml})\end{array}$ \\
\hline $1 \mathrm{y} 7 \mathrm{mth}$ & 19.6 & 224 \\
\hline $1 \mathrm{y} 10 \mathrm{mth}$ & 6.3 & 227 \\
\hline 3 y $10 \mathrm{mth}$ & 12 & - \\
\hline 10 y $7 \mathrm{mth}$ & 146 & - \\
\hline $11 \mathrm{y} 8 \mathrm{mth}$ & 71 & - \\
\hline Mother & 97 & 212 \\
\hline Father & 165 & 504 \\
\hline $\begin{array}{c}\text { Fucosidosis } \\
\text { patients }\end{array}$ & $<1(n=4)$ & $5-24(n=4)$ \\
\hline Heterozygotes & $22-39(n=8)$ & $304-1113(n=4)$ \\
\hline Controls & $30-189$ & $212-1700$ \\
\hline
\end{tabular}

$\alpha$-fucosidase activity measured with the synthetic substrate 4-methylumbelliferyl $\alpha$-L-fucoside.

this deletion by slipping during replication. ${ }^{37}$ This patient is 7 years old but severely affected. A decreased level of mRNA owing to skipping of exon 1 rather than a truncated protein is probably the cause of the low $\alpha$-fucosidase activity in this patient.

Mutations were not detected in patients 1 and 7. The original diagnosis of fucosidosis in patient 1 was based on low $\alpha$-fucosidase in his serum and cultured fibroblasts. The amount of $\alpha$-fucosidase activity and protein in fibroblasts from patient 1 suggests that this patient has the low activity polymorphism expressed in plasma $^{11}$ and fibroblasts. ${ }^{14}$ This would be consistent with the lack of detection of mutations in his $\alpha$-fucosidase gene and the normal metabolism of fucose labelled compounds in his fibroblasts (B Ulrich-Bott, personal communication). His clinical symptoms, which include general developmental retardation without progression and a slight coarsening of the face but no angiokeratoma, must be the result of another disorder.

The $\alpha$-fucosidase activity in the leucocytes of patient 7 was below the normal reference range and the activity in plasma at the lower end of the reference range between the ages of 1 year 7 months and 3 years 10 months (table 5). The partial deficiency in the leucocytes was the basis of the provisional diagnosis of fucosidosis. The $\alpha$-fucosidase activity in her fibroblasts was similar to that in heterozygotes. The activity in leucocytes of her unrelated parents were within the normal reference range although their plasma $\alpha$-fucosidase activities were in the lower part of the normal reference range, which overlaps that of heterozygotes. However, she had normal levels of activity in her leucocytes at an older age when the clinical progression of the disease had also slowed. She has not had the characteristic urinary oligosaccharide profile for fucosidosis at any age, but does excrete a large amount of a low molecular weight oligosaccharide (unpublished results). It has been suggested as a result of a recent clinical reassessment at the age of 16 that she may have Kivlin (Peters plus) syndrome on the basis of her dysmorphic appearance (M Baraitser, $R$ Winter, personal communication). This would be consistent with our lack of detection of any mutations in the FUCA1 gene. The cause of her transient deficiency of $\alpha$-fucosidase in leucocytes at an early age remains unexplained.
Putative disease causing mutations have been discovered in six out of eight patients, who were diagnosed clinically and biochemically as having fucosidosis. The absence of common mutations and the differences in clinical phenotype of patients with negligible residual $\alpha$-fucosidase activity confirm the heterogeneity in this disorder. All the patients were homozygous for different single mutations or in one case for an allele with two sequence changes. In some cases, it was possible to attribute this homozygosity to consanguinity or to substantiate it by family studies. The five new mutations discovered in this study bring to 20 the number of putative disease causing mutations found in patients with fucosidosis.

We would like to thank Dr Michael Cantz (Heidelberg) for referring patient 1 and his colleague Barbara Ulrich-Bott for carrying out the metabolic studies on the fibroblasts of patient 1 , and Professors James Leonard and Ian Young and Dr Judith Grant for referring patients 7 and 2, respectively. Helen Cragg and Magali Williamson thank the Child Health Research Appeal Trust and the Biotechnology and Biological Sciences Research Council (formerly SERC), respectively, for postgraduate studentships. The support of the Society for Mucopolysacate studentships. The support of the Society for Mucopolysac-
charide Disease is also acknowledged and we thank Dr Sue Malcolm for her advice during this project.
Malide

1 Durand P, Borrone C, Della Cella G. A new mucopolysaccharide lipid-storage disease? Lancet 1966;ii:1313-14.

2 Van Hoof F, Hers HG. Mucopolysaccharidosis by absence of $\alpha$-fucosidase. Lancet 1968;i:798.

3 Willems PJ, Gatti R, Darby JK, et al. Fucosidosis revisited: a review of 77 patients. Am F Med Genet 1991;38:71-131.

4 Willems PJ, Garcia CA, De Smedt MCH, et al. Intrafamilial variability in fucosidosis. Clin Genet 1988;34:7-14.

5 Vellodi A, Cragg HM, Winchester B, et al. Allogeneic bone marrow transplantation for fucosidosis. Bone Marrow Transplant 1995;15:153-8.

6 Taylor RM, Farrow BRH, Stewart GJ, Healy PJ, Tiver K. The clinical effects of lysosomal enzyme replacement by bone marrow transplantation after total lymphoid irradiation on neurological disease in fucosidase-deficient dogs. Transplant Proc 1988;20:89-93.

7 Fowler ML, Nkai H, Byers MG, et al. Chromosome 1 localisation of the human-alpha-L-fucosidase structural gene with a homologous site on chromosome 2 . Cytogenet
gemal gene with a homologous site
Cell Genet 1986;43:103-8.

8 Kretz KA, Cripe D, Carson GS, Fukushima H, O'Brien JS. Structure and sequence of the human $\alpha$-L-fucosidase gene and pseudogene. Genomics 1992;12:276-80.

9 O'Brien JS, Willems PJ, Fukushima H, et al. Molecular biology of the alpha-L-fucosidase gene and fucosidosis. Enzyme 1987;38:45-53.

10 Occhiodoro T, Beckman KR, Morris CP, Hopwood JJ. cDNA clones. Biochem Biophys Res Commun 1989;164:439 45.

$11 \mathrm{Ng}$ WG,Donnell GN, Koch R. Serum alpha fucosidase activity in the diagnosis offucosidosis. Pediatr Res 1973;7: 391.

12 Eiberg $H$, Mohr J, Neilsen LS. Linkage of plasma $\alpha$-L-fucosidase (FUCA2) and the plasminogen (PLG) system Clin Genet 1984,26:23-9.

13 Murray JC, Beutow KH, Donovan M, et al. Linkage disequilibrium of plasminogen polymorphisms and assignments of the gene to human chromosome 6q26-6q27. Am F Hum Genet 1987;82:338-50.

14 Van Elsen AF, Leroy JG, Wauters FJ, Willems PJ, Buyaert $\mathrm{C}$, Verheyen $\mathrm{K}$. In vitro expression of $\alpha$-L-fucosidase activity polymorphism observed in plasma. Hum Mol Genet 1983;64:235-9.

15 Kretz KA, Darby JK, Willems PJ, O'Brien JS. Characterization of EcoR1 mutation in fucosidosis patients: a stop codon in the open reading frame. $\mathcal{f} \mathrm{Mol}$ Neurosci 1989;1:177-80.

16 Yang $M$, Allen $\mathrm{H}$, DiCioccio RA. A mutation generating a stop codon in the $\alpha$-L-fucosidase gene of a fucosidosis stop codon in the $\alpha-L$-fucosidase gene of a fucosidosis

17 Seo HC, Willems PJ, Kretz KA, Martin BM, O'Brien JS. Fucosidosis: four new mutations and a new polymorphism. Hum Mol Genet 1993;2:423-9.

18 Seo HC, Willems PJ, O'Brien JS. Six additional mutations in fucosidosis: three nonsense mutatons and three frameshift mutations. Hum Mol Genet 1993;2:1205-8.

19 Williamson $M$, Cragg $\mathrm{H}$, Grant J, et al. A 5 ' splice site mutation in fucosidosis. $\mathcal{F}$ Med Genet 1993;30:21 8-23.

20 Seo HC, Kunze J, Willems PJ, Kim AH, Hanefeld F, O'Brien JS. A single-base deletion mutation in a Turkish patient with fucosidosis. Hum Mutat 1994;3:407-8.

21 Seo HC, Yang M, Tonlorenz LR, et al. A missense mutation (S63L) in $\alpha$-L-fucosidase is responsible for fucosidosis in an Italian patient. Hum Mol Genet 1994;3:2065-6. 
22 Seo HC, Heidemann PH, Lutz E, O'Brien JS. A nonsense mutation in two German patients with fucosidosis. Hum Mutat 1995;6:184-5.

23 Seo HC, Yang M, Kim AH, O'Brien JS, DiCioccio RA, Gordon BA. A 66-bp insertion in exon 6 of the $\alpha$-L-fucosidase gene of a fucosidosis patient. Hum Mutat 1996;7:183.

24 Whiteman P, Young E. The laboratory diagnosis of Sanfilippo disease. Clin Chim Acta 1977;76:139-47.

25 Andrews GL, Alhadeff JA. Radioimmuno-assay determination of decreased amounts of $\alpha$-L-fucosidase protein in fucosidosis. Biochim Biophys Acta 1982;715:90-8.

26 Johnson SW, Plesecki S, Wang RF, Damjanov I, Alhadeff JA. Analysis of purified human liver $\alpha-\mathrm{L}-$ fucosidase by western
blotting with lectins and polyclonal and monoclonal blotting with lectins and polyclonal

27 Davies J, Christomanou H, Winchester B, Malcolm S. Detection of 8 new mutations in $\alpha$-galactosidase $A$ gene in Fabry disease. Hum Mol Genet 1993;3:667-9.

28 Cragg H, Seo HC, O'Brien J, Swallow D, Winchester B. Molecular basis of the commom electrophoretic polymorphism (Ful/Fu2) in human $\alpha$-L-fucosidase. $\mathcal{F}$ Med Genet 1994;31:659-60.

29 Fisher KJ, Aronson NN. Isolation and sequence analysis of a cDNA encoding rat liver $\alpha$-L-fucosidase. Biochem $\mathcal{F} 1989$; 264:695-701.
30 Skelly BJ, Sargan DR, Herrtage ME, Winchester BG. The molecular defect underlying canine fucosidosis. $\mathcal{F} \mathrm{Med}$ Genet 1996;33:284-8.

31 Bock A, Fang-Kircher S, Braun F, et al. Another unusua case of fucosidosis. F Inherited Metab Dis 1995;18:93-4.

32 Nako S, Takenaka T, Maeda $M$, et al. An atypical variant of Fabry's disease in men with left ventricular hypertrophy. $N$ Engl ₹ Med 1995;333:288-93.

33 Hopwood JJ, Bunge S, Morris CP, et al. Molecular basis of 2-sulphatase gene. Hum Mutat 1993;2:435-42.

34 Scott HS, Bunge S, Gal A, Clarke LA, Morris CP, Hopwood JJ. Molecular genetics of mucopolysaccharidosis typ J. Molecular genetics of mucopolysaccharidosis type 1: diagnostic, clinical, and biological implications. Hum Mutat

35 Shapiro MB, Senapathy P. RNA splice junctions of different classes of eukaryotes; sequence statistics and functional implications in gene expression. Nucleic Acids Res 1987;15: 7155-75.

36 Fritsch G, Paschke E. Fukosidose. Eine seletene angeboren Storung des lysosomalen Glykoproteinstoffwechsels. Padiatr Prax 1988;37:469-76.

37 Krawezak M, Cooper D. Gene deletions causing human genetic disease: mechanism of mutagenesis and the role of the local DNA sequencing environment. Hum Mol Genet 1991;86:425-41. 